D. Keith Rose MD FRCPC, ${ }^{*} \dagger$

Robert J. Byrick MD FRCPC, ${ }^{*} \dagger$

Marsha M. Cohen MD FRCPC, $† \S$ Gary M. Caskennette*

\section{Planned and unplanned postoperative admissions to critical care for mechanical ventilation}

Preoperatively, age $\geq 60$ yr and common systemic illnesses (cardiac, renal, pulmonary) were markers for planned admission, but only positive HIV status was a risk factor for unplanned admission. The two main physiological features which identified all critical care admissions were haemoglobin oxygen saturation $<90 \%$ (preoperatively breathing room air and intraoperatively) and tachycardia during the operative period. Six of ten of the unplanned after PACU discharge patients underwent bronchoscopy with a neurolept analgesic technique.

Conclusion: Postoperative admissions to a critical care unit, both planned and unplanned, are uncommon. This study has identified haemoglobin oxygen desaturation during the perioperative period and intraoperative tachycardia as important markers for all admissions to critical care.

Objectif: Dans le but de déterminer les facteurs qui influencent l'admission à l'unité aux soins intensifs et à la ventilation postopératoire, les auteurs ont étudié l'incidence, la chronologie, les causes et les facteurs de risques pertinents à la période de $48 h$ qui suit une intervention chirurgicale (chirurgie cardiaque et neurochirurgie excluses).

Méthodes: Les patients ont été répartis ainsi: admission prévue en préopératoire; admission non prévue et décidée en salle d'opération ou à la salle de réveil; et admission non planifiée décidée après le départ de la salle de réveil. Le pourcentage d'admission par catégorie pour ceux qui possédaient ces caractéristiques préopératoires et peropératoires spécifiques ont été comparées avec ceux qui n'avaient pas de facteurs de risque prédisposants à l'admission $(P<0.01)$.

Résultats: Seulement 329 patients sur 15059 (2,2\%) ont été admis aux soins intensifs. De ces admissions, 288 avaient été prévues, 31 décidées en salle d'opération ou à la salle de rêveil, et 10 après leur congé de la salle de réveil. La cause de l'admission dans $75 \%$ des cas imprévus était d'origine respiratoire. En préopératoire, l'âge ( $>60$ ans) et une maladie systémique commune (cardiaque, rénale, pulmonaire) ont constitué des indications pour les admissions non planifiées, dont un seul cas de positivité HIV, considéré comme facteur de risque. Les deux caractéristiques physiologiques principales, pour 
une admission aux soins intensifs ont été une baisse de saturation $<90 \%$ (en préopératoire à l'air libre ou pendant l'intervention) et la tachycardie peropératoire. Six des dix patients admis après leur congé de la salle de réveil ont subi une bronchoscopie sous neuroleptanalgésie.

Conclusion: Les admissions postopératoires à l'unité de soins intensifs, qu'elles soient planifiées ou non, sont peu fréquentes. Cette étude identifie la désaturation en oxygène aux périodes pré- et peropératoires comme des indications déterminantes de toutes les admissions aux soins intensifs.

Over $40 \%$ of critical care admissions are for postoperative patients. ${ }^{1-3}$ It is much more costly to treat postoperative patients in a critical care unit than with routine ward care. ${ }^{4}$ We are unaware of any studies which have prospectively examined factors which may influence the clinician in choosing critical care admission and postoperative ventilation.

Both mortality and major morbidity after anaesthesia are uncommon, and they are influenced by many nonanaesthetic factors. $^{5-7}$ However, an unplanned admission to a critical care unit for mechanical ventilation within $48 \mathrm{hr}$ of surgery is an event that most patients and physicians would consider to be an important adverse outcome. This outcome presupposes that neither the surgeon nor the anaesthetist anticipated preoperatively that critical care admission for mechanical ventilation would be needed after surgery. The ASA Closed Claims study has emphasized the need to investigate "sentinel events" and to develop preventative strategies for high risk groups. ${ }^{8}$ Thus, to develop preventative strategies, information must be gathered on how clinicians identify patients (or fail to identify patients) who are admitted to a critical care unit for postoperative ventilation.

In this study we examine the incidence, reasons, and timing of critical care admissions for postoperative ventilation within $48 \mathrm{hr}$ of noncardiac and nonneurosurgical procedures at a tertiary-care hospital. For patients with critical care admissions for mechanical ventilation, we identified those whose admission was planned and those whose admission was unplanned. We also determined whether preoperative, intraoperative, and immediate postoperative risk factors can identify patients for critical care admission and mechanical ventilation.

\section{Methods}

Following institutional Ethics approval, we prospectively collected information on consecutive surgical cases from April 1, 1991 to June 30, $1993(n=15,059)$ at St. Michael's Hospital, Toronto, Canada, a 400-bed, tertiary-care referral centre affiliated with the University of
Toronto. Facilities for mechanical ventilation of all noncardiac and nonneurosurgical patients were located in a single critical care unit.

All patients who had at least one overnight stay after surgery were included in the analysis, but outpatients (no overnight stay) were not. Cardiac and neurosurgical cases were excluded because most of these cases were routinely admitted postoperatively to separate critical care units. Patients who were admitted to the critical care unit before surgery were excluded. Those whose lungs were not mechanically ventilated postoperatively but who required an increased level of nursing care from routine ward care either planned or unplanned (e.g., Coronary Care Unit, Step-down Unit, or the Critical Care Unit) were also omitted from the study. For this latter group, the criteria for this increased level of care without mechanical ventilation were not clearly defined. Only if these patients received mechanical ventilation in the critical care unit within $48 \mathrm{hr}$ of the surgical procedure, were they included in the final analysis. For the purposes of our study, the number of cases (the denominator) was defined as the number of operating room visits rather than the number of patients, since some patients were in the operating room on more than one occasion. As this was a study of usual care, no attempt was made to influence the anaesthetist's choice of anaesthetic or postoperative management.

Data on patients were collected from three hospital databases. The first was from duplicate copies of anaesthetic records on all patients attended by an anaesthetist in the operating room and included age, ASA physical status, and preoperative illnesses. ${ }^{9}$ Unplanned critical care admission from the OR or PACU was identified by a specific adverse event notation (tick box) on the OR or PACU record completed either by the anaesthetist or by the PACU nurse who had been trained in defining and recording such occurrences. The Appendix gives definitions of the variables on preoperative assessment, intraoperative adverse events and PACU complications collected in the anaesthesia database.

The second database contained details on each patient's admission to the critical care unit for postoperative ventilation (e.g., duration of ventilation and length of stay). ${ }^{10}$ Unique numbers assigned to each patient on hospital admission allowed us to merge databases so that we could identify patients who were admitted to critical care for postoperative ventilation and those who were not. The durations of hospital stay and in-hospital mortality were added from a third database compiled by the hospital.

To identify risk factors for admission to critical care and mechanical ventilation, we categorized the patients admitted to critical care into three groups (see Figure 1): 
(i) The PLANNED group included patients for whom the anaesthetist decided preoperatively that critical care admission and postoperative ventilation would be necessary. This group included patients who had additional unscheduled surgical procedures with a planned critical care admission for mechanical ventilation. (ii) The UNPLANNED OR/PACU group were those whose need for postoperative ventilation was not anticipated preoperatively but were admitted to critical care due to some problem recognized in the OR or PACU. Mechanical ventilation was commenced within $48 \mathrm{hr}$ of the completion of the operation. (iii) The UNPLANNED POST PACU group included patients whose need for postoperative ventilation and critical care admission was recognized after discharge from the PACU but within $48 \mathrm{hr}$ of surgery.

A chart review for every patient in the two unplanned groups was carried out by one author (DKR) to determine the reasons for postoperative ventilation. These were divided into three major categories: neurological (unexpected depressed level of consciousness or new stroke), cardiac (pulmonary oedema on $x$-ray, prolonged hypotension with inotrope support, new unstable dysrhythmia, or cardiac arrest), or respiratory; either hypoventilation, (respiratory rate $>30 \mathrm{~min}^{-1}$, clinical fatigue and/or elevated $\mathrm{PCO}_{2}$ ), atelectasis/pneumonia (on $x$-ray), or upper airway obstruction (any cause which did or could produce stridor or laryngospasm). Each patient could have had more than one reason for admission to the critical care unit for mechanical ventilation.

We first determined the rate of critical care admission (PLANNED, UNPLANNED OR/PACU, UNPLANNED POST PACU) for all study patients. To determine risk factors for critical care admission for mechanical ventilation, we next compared the rate of critical care admission for cases with specific characteristics compared with the rate for those in a reference group who did not have the characteristic of interest. For example, we compared the rate of admission for men with the rate of admission for women and patients $\geq 60 \mathrm{yr}$ of age with those $<60$ yr. A specific factor would be identified as placing a patient at greater risk of critical care admission if the rate of admission was greater in patients with the characteristic than for the reference group. Statistical significance was determined using the chi-squared statistic $(P<0.01)$. For patients with a systemic illness, the reference groups were those with no major systemic illness.

\section{Results}

Following 15,059 operative procedures during the study, 329 cases (2.2\% of inpatient procedures) had a

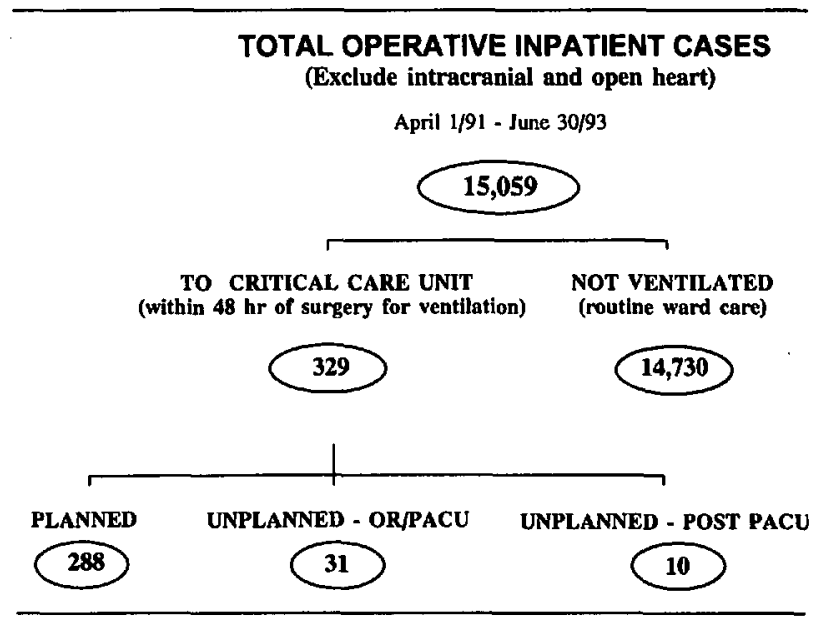

FIGURE 1 Postoperative care for all patients $(n=15,059)$ for the 48-hr period after surgery completed. For this inpatient population, excluding cardiac and neurosurgical procedures, $2.2 \%(n=329)$ were admitted to critical care for mechanical ventilation. For those who were admitted for postoperative ventilation, 31 were unplanned but recognized either in the operating room or PACU, and 10 were unplanned and recognized after PACU discharge.

critical care admission and ventilatory support within 48 $\mathrm{hr}$ of the operation (Figure 1). For those with a critical care admission and mechanical ventilation, $288(87.5 \%)$ were scheduled preoperatively (PLANNED), 31 were identified in the OR or PACU (UNPLANNED OR/PACU), and 10 after PACU discharge (UNPLANNED POST PACU).

For the unplanned patients, respiratory problems predominated (24 of 31 from the OR/PACU group, and nine of 10 from the POST PACU group) as the reason for admission. Cardiac related reasons occurred in nine of 31 in the OR/PACU group and three of 10 of the POST PACU cases, but a neurological aetiology was rare (four of the OR/PACU and none of the POST PACU group). A combination of respiratory and cardiac causes was noted in four of the OR/PACU group and in two of POST PACU group.

For those who had a respiratory reason for unplanned admission to critical care for mechanical ventilation, seven of $24(29.2 \%)$ in the OR/PACU group were diagnosed as having atelectasis/pneumonia compared with eight of nine (88.9\%) in the POST PACU group (Figure $2-P<0.05)$ ). For the OR/PACU patients, 14 had their tracheas extubated following the operative procedure but later required tracheal reintubation - four in the OR, seven in the PACU, and three in the critical care unit. All of the POST PACU group required tracheal intubation after PACU discharge, and in eight of 10, their critical care admission and ventilatory support occurred more than six hours following the completion of the operation. 


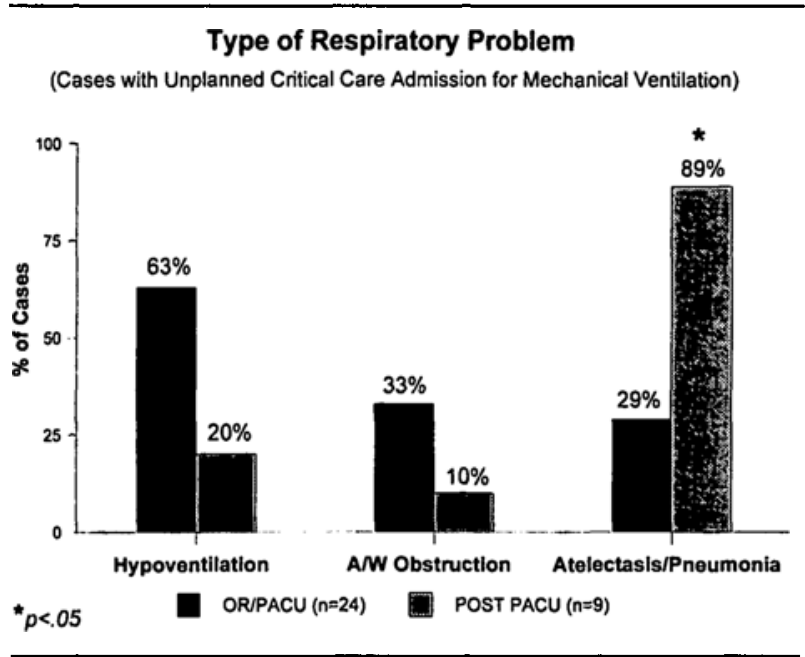

FIGURE 2 Type of respiratory problem (hypoventilation, airway obstruction, atelectasis/pneumonia) in those patients who had an unplanned admission to the critical care unit for mechanical ventilation either from the operating room or PACU $(n=24)$ or after PACU discharge $(n=9)$. Atelectasis/pneumonia was a responsible cause in $29 \%$ of the unplanned admissions from the OR or PACU but increased to 89\% in those who were not recognized until after PACU discharge.

\section{Preoperative patient characteristics (Table I)}

Compared with the reference population, the rate of PLANNED admission was higher in patients who were male, ASA physical status $4-5$, and $\geq 60$ yr. For example, $2.5 \%$ of all men in the study population had a PLANNED admission compared with only $1.3 \%$ of the reference group (women) $(P<0.01)$. As well, PLANNED critical care admissions for mechanical ventilation were more common in smokers, those with chronic obstructive pulmonary disease, heart disease, and renal disease than in those with no preoperative illness. Those with room air haemoglobin oxygen saturation $<90 \%$ were more likely to have a PLANNED admission than patients whose haemoglobin oxygen saturation was $\geq 90 \%$.

Factors identified with increased risk for both unplanned groups did not include common systemic illnesses and were limited to preoperative room air haemoglobin saturation $<90 \%$ and a positive HIV status.

Examining these two factors more closely revealed that haemoglobin oxygen saturation whilst breathing room air, measured in 10,841 patients in the study population, was $<90 \%$ in only 118 cases. For these 118 patients, $16.1 \%(n=19)$ were in the PLANNED group, $5.9 \%(n=7)$ in the UNPLANNED OR/PACU group, and $3.5 \%(n=4)$ in the UNPLANNED POST PACU group. The rates of admission for those with room air haemoglobin oxygen desaturation were greater than the rates for patients who did not have room air haemoglo- bin oxygen desaturation. The second characteristic which distinguished the unplanned groups was positive HIV status. In the total population studied, 89 patients were known to be HIV positive, and a total of $5.6 \%$ $(n=5)$ of these $(1.1 \%$ in the UNPLANNED OR/PACU and $4.5 \%$ in the UNPLANNED POST PACU) had an unplanned critical care admission for mechanical ventilation, rates much higher than those who had no systemic illness preoperatively.

\section{Surgical, anaesthetic, and intraoperative characteristics} (Table II)

Emergency cases and those undergoing abdominal operations distinguished those patients at increased risk of a PLANNED admission. Intraoperative problems (hypotension, tachycardia, dysrhythmia, haemoglobin oxygen desaturation, and increased requirement for packed cells) increased risk of a planned admission compared with those without problems.

Patients who were emergency cases and who had major abdominal procedures were also more likely to be in the UNPLANNED OR/PACU group. As well, these patients were more likely to have had problems during their intraoperative course. These problems included haemoglobin oxygen desaturation, either in the operating room or in the PACU, and intraoperative tachycardia.

The most distinguishing feature of the 10 UNPLANNED POST PACU cases was that of undergoing bronchoscopy with a neurolept analgesic technique (6/10 patients). For the entire study population there were 525 bronchoscopies completed with a neurolept analgesic technique, and six of these were eventually part of the UNPLANNED POST PACU group. In this UNPLANNED POST PACU group other intraoperative risk factors identified were haemoglobin oxygen desaturation and tachycardia.

Intraoperative haemoglobin oxygen desaturation was noted in only 136 of the study population, and $10.3 \%$ ( $n$ $=14$ ) occurred in the PLANNED group, $5.9 \%(n=8)$ in the OR/PACU group, and $1.5 \%(n=2)$ in the POST PACU group. These rates of admission were higher than those in patients without intraoperative haemoglobin desaturation. For the entire population, 383 episodes of intraoperative tachycardia were recorded; $8.3 \%(n=32)$ in the PLANNED group, $2.1 \%(n=8)$ in the OR/PACU group, and $1.0 \%(n=4)$ in the POST PACU group. All these rates of admission were higher than in those without tachycardia.

\section{Outcome following critical care admission and} mechanical ventilation (Table III)

Long-term outcomes were worse for the UNPLANNED than for the PLANNED ventilation group. The mean 
TABLE I Percentage of patients with specific preoperative characteristics who had critical care admission . and mechanical ventilation

\begin{tabular}{|c|c|c|c|c|}
\hline \multirow[b]{2}{*}{ Number of patients } & & \multicolumn{3}{|c|}{ Critical care admission } \\
\hline & & $\begin{array}{l}\text { Planned } \\
\text { ventilation } \\
288\end{array}$ & $\begin{array}{l}\text { Unplanned } \\
\text { from OR/PACU } \\
31\end{array}$ & $\begin{array}{l}\text { Unplanned } \\
\text { POST PACU } \\
10\end{array}$ \\
\hline Characteristic (Reference group) & $n$ & $\%$ & $\%$ & $\%$ \\
\hline Male (female) & 7,531 & $2.5(1.3)^{*}$ & $0.2(0.2)$ & $0.1(0.03)$ \\
\hline $\begin{array}{l}\text { ASA physical status } 4-5 \text { (ASA physical } \\
\text { status } 1-3 \text { ) }\end{array}$ & 438 & $24.8(1.2)^{*}$ & $1.1(0.2)^{*}$ & $0.2(0.06)$ \\
\hline Age $\geq 60$ yr $(<60 \mathrm{yr})$ & 5,617 & $3.5(1.0)^{*}$ & $0.2(0.2)$ & $0.04(0.1)$ \\
\hline Smoker (nonsmoker) & 3,711 & $2.5(1.7)^{*}$ & $0.3(0.2)$ & $0.05(0.07)$ \\
\hline COPD (no illness $\dagger$ ) & 781 & $7.4(0.6)^{*}$ & $0.4(0.1)$ & $0(0.03)$ \\
\hline Renal disease (no illness $\dagger$ ) & 1,011 & $5.1(0.6)^{*}$ & $0.3(0.1)$ & $0(0.03)$ \\
\hline HIV +ve (no illness $\dagger$ ) & 89 & $2.2(0.6)$ & $1.1(0.1)^{*}$ & $4.5(0.03)^{*}$ \\
\hline Heart disease (no illness $\dagger$ ) & 1,443 & $7.8(0.6)^{*}$ & $0.3(0.1)$ & $0(0.03)$ \\
\hline $\mathrm{SpO}_{2}$ breathing Room Air $<90 \%(\geq 90 \%)$ & 118 & $16.1(1.8)^{*}$ & $5.9(0.2)^{*}$ & $3.5(0.04)^{*}$ \\
\hline
\end{tabular}

$n=$ Number of patients with the specific characteristic (total population $n=15,059$ ).

$\%=$ Percentage of patients with the specific characteristic who had a critical care admission - PLANNED, UNPLANNED OR/PACU, UNPLANNED POST PACU. (For each reference group, the rates of admission are noted in brackets).

$\dagger$ Patients with no illness $n=5,748$.

*Denotes a difference from patients in the reference group $(P<0.01)$.

TABLE II Percentages of patients with specific surgical, anaesthetic, intraoperative, and PACU characteristics who had critical care admission and mechanical ventilation

\begin{tabular}{|c|c|c|c|c|}
\hline \multirow[b]{2}{*}{ Number of patients } & & \multicolumn{3}{|c|}{ Critical care admission } \\
\hline & & $\begin{array}{l}\text { Planned } \\
\text { ventilation } \\
288\end{array}$ & $\begin{array}{l}\text { Unplanned } \\
\text { from OR/PACU } \\
31\end{array}$ & $\begin{array}{l}\text { Unplanned } \\
\text { POST PACU } \\
10\end{array}$ \\
\hline Characteristic (Reference group) & $n$ & $\%$ & $\%$ & $\%$ \\
\hline Emergency (nonemergency) & 1,893 & $5.2(1.4)^{*}$ & $0.7(0.1)^{*}$ & $0.05(0.07)$ \\
\hline Abdominal surgery (†other) & 2,700 & $5.0(1.3)^{*}$ & $0.4(0.2)^{*}$ & $0.04(0.03)$ \\
\hline Bronchoscopy (†other) & 685 & $0.7(1.3)$ & $0.3(0.2)$ & $0.9(0.03)^{*}$ \\
\hline Neurolept technique (GA) & 2,762 & 0 & $0.04(0.3)$ & $0.2(0.03)^{*}$ \\
\hline OR hypotension (no hypotension) & 294 & $11.9(1.7)^{*}$ & $2.7(0.2)^{*}$ & $0.3(0.06)$ \\
\hline OR tachycardia (no tachycardia) & 383 & $8.3(1.7)^{*}$ & $2.1(0.2)^{*}$ & $1.0(0.04)^{*}$ \\
\hline Intraop pulmonary oedema (no $\mathrm{PE}$ ) & 6 & $16.6(1.9)^{*}$ & $50.0(0.2)^{*}$ & 0 \\
\hline Intraop dysrhythmia (no dysrhythmia) & 126 & $12.7(1.8)^{*}$ & $2.3(0.2)^{*}$ & 0 \\
\hline Intraop $\geq 6$ units packed cells ( $<6$ units) & 32 & $65.6(1.8)^{*}$ & $6.2(0.2)^{*}$ & 0 \\
\hline$>2$ laryngoscopies ( $\leq 2$ laryngoscopies) & 182 & $3.8(1.9)$ & $1.1(0.2)^{*}$ & 0 \\
\hline $\mathrm{SpO}_{2}<90 \%$ intraop $(\geq 90 \%)$ & 136 & $10.3(1.8)^{*}$ & $5.9(0.2)^{*}$ & $1.5(0.05)^{*}$ \\
\hline $\mathrm{SpO}_{2}<90 \%$ in PACU $(\geq 90 \%)$ & 1,357 & N/A & $1.0(0.05)^{*}$ & $0.4(0.03)^{*}$ \\
\hline \multicolumn{5}{|l|}{ Inadequate relaxant reversal noted in } \\
\hline PACU (adequate) & 39 & N/A & $5.1(0.1)^{*}$ & 0 \\
\hline
\end{tabular}

$n=$ Number of patients with the specific characteristic (total population $n=15,059$ ).

$\%=$ Percentage of patients with the specific characteristic who had a critical care admission - PLANNED, UNPLANNED OR/PACU, UNPLANNED POST PACU. (For each reference group, the rates of admission are noted in brackets).

fOther - all nonbronchoscopy and nonabdominal procedures, $n=11,674$.

*Denotes a difference from patients in the reference group $(P<0.01)$. 
TABLE III Outcome following critical care admission and mechanical ventilation

\begin{tabular}{llll}
\hline & \multicolumn{3}{l}{ Critical care admission } \\
\cline { 2 - 4 } & $\begin{array}{l}\text { Planned } \\
\text { ventilation }\end{array}$ & $\begin{array}{l}\text { Unplanned } \\
\text { from OR/PACU }\end{array}$ & $\begin{array}{l}\text { Unplanned } \\
\text { POST PACU }\end{array}$ \\
\hline Number of patients & 288 & 31 & 10 \\
Outcome & & & \\
Duration of ventilation (days) & $3.1 \pm 6.6$ & $5.1 \pm 13.7$ & $17.4 \pm 19.2$ \\
LOS in critical care unit (days) & $6.0 \pm 24.7$ & $8.9 \pm 25.8$ & $15.2 \pm 18.9$ \\
LOS in hospital (days) & $21.5 \pm 20.9$ & $26.8 \pm 32.1$ & $26.2 \pm 23.9$ \\
& 14.4 & 6.5 & $60.0^{*}$ \\
\hline
\end{tabular}

*Denotes a difference from PLANNED group $(P<0.01)$.

duration of ventilation, length of stay in the critical care unit and length of stay in hospital were numerically but not statistically greater for the unplanned groups. The mortality rate for the UNPLANNED POST PACU group, six of 10 patients, was higher than that documented in the other two groups admitted to intensive care $(P<0.01)$.

\section{Discussion}

The use of postoperative ventilation following surgery was uncommon in our hospital. Anaesthetists planned ahead for $88 \%$ of patients (288 of 329) admitted for postoperative mechanical ventilation. Only in $12 \%$ (41 of 329) did they not foresee a need for postoperative ventilation, and in only 10 of these unplanned patients did they not recognize this need until after PACU discharge.

The characteristics for the PLANNED group were not unexpected. In their preoperative assessments, anaesthetists considered age, ASA physical status, and major illnesses (cardiac, renal, and pulmonary) when determining the need for postoperative ventilation. Our data do not permit us to assess the appropriateness of these decisions, and we do not know which of the patients in the PLANNED group benefitted from critical care admission and mechanical ventilation given that length of stay was long and that mortality rate was high. For the two unplanned groups, unlike the PLANNED group, neither age nor major illness, except positive HIV status, predicted these patients preoperatively.

In addition, our study found that an abnormal preoperative haemoglobin oxygen saturation while breathing room air was a factor in identifying patients who needed ventilation later, information that may not have been recognized previously. Overall, this characteristic was uncommon, found in only $0.8 \%$ or 118 cases from the entire population. However, when preoperative room air haemoglobin oxygen saturation was $<90 \%, 16.1 \%$ (19 of 118) of these patients had a planned admission and $9.4 \%$ (11 of 118 ) had an unplanned admission. Low preoperative haemoglobin oxygen saturation should alert the anaesthetist to the lack of cardiorespiratory reserve and the potential need for postoperative ventilatory support.

The number of patients after PACU discharge who received mechanical ventilation was small; only 10 patients. Considering the patient population (four were HIV positive and six underwent a diagnostic bronchoscopy) and their outcome (nine of them required mechanical ventilation for respiratory reasons and six died), this group likely represents patients with underlying pulmonary disease which progressed. Nonetheless, in view of this high mortality for patients admitted after PACU discharge, more studies are needed to clarify additional characteristics and outcomes of this unrecognized group. Knaus has emphasized that location and condition of the patient prior to critical care unit treatment are important factors in predicting outcome., ${ }^{3,11}$ There may also be the need for an intermediate level of care, especially for patients with haemoglobin oxygen desaturation and intraoperative tachycardia who do not need immediate postoperative pulmonary ventilation. ${ }^{12}$

The rates of unrecognized critical care admission for mechanical ventilation in our study are similar to other studies examining unanticipated admissions to a critical care unit. Swann et al., from a retrospective audit of 265 critical care admissions, (not necessarily limited to those who had only mechanical ventilation), determined that $13 \%$ of critical care admissions from their OR or PACU were unanticipated. ${ }^{13}$ In their study, the total number of in-patients examined for this period was about 10,000 , a rate of unplanned admission, $0.3 \%$, that is similar to our results $(0.3 \%)$. In another prospective evaluation of 17,093 surgical patients over a 65 -wk period, Cullen 
reported that the rate of unanticipated postoperative critical care admissions from the OR and PACU was also similar to the present study. ${ }^{14}$

A British study of ICU admissions over a 10-year period identified only 100 patients from a total of 190,000 surgical procedures $(0.05 \%)$, who were admitted to a critical care unit due solely to a complication of anaesthetic technique. ${ }^{15}$ In contrast, our rate of unplanned admission $(0.3 \%)$ reflects many causes related to patient, surgical, or anaesthetic factors. Mathew et al. found an association between anaesthetic management and a slightly different indicator, emergency tracheal intubation in the PACU. ${ }^{16}$ Although our rate of reintubation of patients in the PACU was lower (seven of 14,761 compared with 26 of 13,593 by Mathew et al.), only patients who had PACU tracheal intubation plus unplanned critical care admission and mechanical ventilation were included in our series.

Few studies have attempted to clarify the aetiology of unplanned critical care admissions for mechanical ventilation. Our study emphasizes that respiratory events remain the main reason for unplanned postoperative mechanical ventilation and critical care admission. The appropriateness of anaesthetic management, techniques, and drugs selected for these patients was not assessed in our study. Intraoperative problems were identified as risk factors in both the PLANNED and UNPLANNED OR/PACU groups. Several of these aspects of care are normally managed by the anaesthetist (e.g., fluid replacement and reversal of muscle relaxants), but we were unable to determine if these problems were preventable.

Is an unplanned critical care admission for mechanical ventilation a valid marker of anaesthetic care? Unplanned admissions were so uncommon that this study was only possible when patients were identified from a large anaesthesia database, a system not available at all institutions. As well, the definition of unplanned critical care admission used in studies examining this outcome have differed in their criteria for admission, the time interval after completion of surgery, and the reason for admission. Without standardization, comparisons among institutions are tenuous at best. The reasons for unanticipated critical care admission are multifactorial, and many may be beyond the scope of the anaesthetist's role in patient care. However, unplanned critical care admission for mechanical ventilation as an outcome measure may be a useful indicator of the quality of the overall process of perioperative care. This includes, but is not exclusive to, the anaesthetist's decision to request critical care admission and electively ventilate patients postoperatively.

In summary, we have studied patients who had post- operative ventilation within $48 \mathrm{hr}$ of surgical completion and specifically identified a small number of patients for whom ventilation and critical care admission was unplanned. Those patients who were unrecognized until after discharge from PACU were a small group, frequently had atelectasis/pneumonia, and had high mortality.

Fortunately, postoperative admission for mechanical ventilation to a critical care unit, planned and unplanned, is uncommon. Two factors that we identified for all groups admitted to critical care were haemoglobin oxygen saturation of $<90 \%$ (both while breathing room air before induction of anaesthesia and intraoperatively) and intraoperative tachycardia. The risk factors identified in this study may help the clinician in the decisionmaking process in choosing critical care admission and postoperative ventilation.

\section{Acknowledgements}

The authors wish to thank Ms. Mary Tan for the compilation of the data and Dr. Michael Kolton for his assistance in writing this manuscript.

\section{Appendix}

\section{Variables examined}

Preoperative

- Haemoglobin desaturation breathing room air - $\mathrm{SpO}_{2}$ $<90 \%$, prior to induction of anaesthesia.

- COPD - chronic obstructive pulmonary disease with cough and/or shortness of breath.

- Renal disease $-\mathrm{Cr}>140 \mu \mathrm{g} \cdot \mathrm{ml}^{-1}$.

- Cardiac disease - valve lesion, angina, or previous infarction.

- Positive HIV status - known to have tested positive for human immunodeficiency virus.

- Other illnesses - hypertension, previous cerebral vascular accident, diabetes.

Intraoperative variables

- Emergency - surgical procedure started within a 12hr period after operative scheduling.

- Type of surgery - based on International Classification of Disease Codes (ninth revision) and further subdivided into 18 categories based on physiological trespass. ${ }^{17}$

- Anaesthetic technique - general anaesthesia, regional, or neurolept analgesia.

Intraoperative problems

- Haemoglobin oxygen desaturation $-\mathrm{SpO}_{2}<90 \%$ at any time

- Tachycardia - $120 \mathrm{bpm}>10 \mathrm{~min}$.

- Hypotension - blood pressure $<80 \mathrm{mmHg}>15 \mathrm{~min}$.

- Dysrhythmia - new atrial fibrillation, supraventricu- 
lar tachycardia, heartblock or premature ventricular contractions $>$ five minutes.

- Difficult tracheal intubation - > two laryngoscopies.

- Pulmonary oedema - frothy sputum and crackles on auscultation.

- Major blood loss - $\geq$ six units packed red blood cells in the operating room.

Post anaesthetic care unit (PACU) events

- Haemoglobin oxygen desaturation $-\mathrm{SpO}_{2}<90 \%$ at any time

- Inadequate relaxant reversal - weakness and inability to maintain head lift $>$ five seconds.

- Other PACU events - hypotension, tachycardia, pulmonary oedema.

\section{References}

1 Knaus WA, Wagner DP, Draper EA, Lawrence DE, Zimmerman JE. The range of intensive care services today. JAMA 1981; 246: 2711-6.

2 Knaus WA, Draper EA, Wagner DP, Zimmerman JE. An evaluation of outcome from intensive care in major medical centers. Ann Intern Med 1986; 104: 410-8.

3 Knaus WA, Wagner DP, Draper EA, et al. The APACHE III Prognostic System. Risk prediction of hospital mortality for critically ill hospitalized adults. Chest 1991; 100: 1619-36.

4 Norris $C$, Jacobs $P$, Rapoport J, Hamilton $S$. ICU and non-ICU cost per day. Can J Anaesth 1995; 42: 192-6.

5 Cohen MM, Duncan PG, Tate RB. Does anesthesia contribute to operative mortality? JAMA $1988 ; 260: 2859-63$.

6 Keenan RL, Boyan CP. Cardiac arrest due to anesthesia. A study of incidence and causes. JAMA 1985; 253: 2373-7.

7 Forrest JB, Rehder K, Cahalan MK, Goldsmith CH. Multicenter study of general anesthesia. III. Predictors of severe perioperative adverse outcomes. Anesthesiology 1992; 76: 3-15.

8 Caplan RA. Adverse outcomes in anesthesia practice. ASA Refresher Course Series 1994; 151:1-7.

9 Rose DK, Cohen MM, Wigglesworth DF, Yee DA. Development of a computerized database for the study of anaesthesia care. Can J Anaesth 1992; 39: 716-23.

10 Byrick RJ, Caskennette GM. Audit of critical care: aims, uses, costs and limitations of a Canadian system. Can J Anaesth 1992; 39: 260-9.

11 Zimmerman JE, Wagner DP, Knaus WA, Williams JF, Kolakowski D, Draper EA. The use of risk predictions to identify candidates for intermediate care units. Implications for intensive care utilization and cost. Chest 1995; 108: 490-9.

12 Byrick RJ, Mazer CD, Caskennette GM. Closure of an intermediate care unit. Impact on critical care utilization. Chest 1993; 104: 876-81.

13 Swann D, Houston P, Goldberg J. Audit of intensive care unit admissions from the operating room. Can J Anaesth 1993; 40: 137-41.

14 Cullen DJ, Nemeskal AR, Cooper JB, Zaslavsky A, Dwyer $M J$. Effect of pulse oximetry, age, and ASA physical status on the frequency of patients admitted unexpectedly to a postoperative intensive care unit and the severity of their anesthesia-related complications. Anesth Analg 1992; 74:181-8.

15 Leigh JM, Tytler JA. Admissions to the intensive care unit after complications of anaesthetic techniques over 10 years. 2. The second 5 years. Anaesthesia 1990; 45: 814-20.

16 Mathew JP, Rosenbaum SH, O'Connor T, Barash PG. Emergency tracheal intubation in the postanesthesia care unit: physician error or patient disease? Anesth Analg 1990; 71: 691-7.

17 Rose $D K$, Cohen $M M$, Rogers $K H$. Is recovery room morbidity related to the surgical procedure? Can J Anaesth 1991; 38: A50. 